\title{
BMJ Open Using an extended theory of planned behaviour to predict smoking cessation counsellors' intentions to offer smoking cessation support in the Taiwanese military: a cross-sectional study
}

\author{
Yu-Lung Chiu, ${ }^{1,2}$ Yu-Ching Chou, ${ }^{1}$ Yaw-Wen Chang, ${ }^{3,4}$ Chi-Ming Chu, ${ }^{1}$ \\ Fu-Gong Lin, ${ }^{1}$ Ching-Huang Lai, ${ }^{1}$ Shu-Ling Hwang, ${ }^{5}$ Wen-Hui Fang, ${ }^{4}$ \\ Senyeong $\mathrm{Kao}^{1,2}$
}

To cite: Chiu Y-L, Chou Y-C, Chang $\mathrm{Y}-\mathrm{W}$, et al. Using an extended theory of planned behaviour to predict smoking cessation counsellors' intentions to offer smoking cessation support in the Taiwanese military: a crosssectional study. BMJ Open 2019;9:e026203. doi:10.1136/ bmjopen-2018-026203

- Prepublication history for this paper is available online To view these files, please visit the journal online (http://dx.doi org/10.1136/bmjopen-2018026203).

Received 24 August 2018 Revised 11 February 2019 Accepted 12 February 2019
Check for updates

(c) Author(s) (or their employer(s)) 2019. Re-use permitted under CC BY-NC. No commercial re-use. See rights and permissions. Published by BMJ.

For numbered affiliations see end of article.

Correspondence to Professor Senyeong Kao; ka0@mail.ndmctsgh.edu.tw

\section{ABSTRACT}

Objectives To use the extended theory of planned behaviour (TPB) to predict smoking cessation counsellors' intentions to offer smoking cessation support.

Design Cross-sectional study

Setting Taiwanese military

Participants A survey of 432 smoking cessation

counsellors was conducted in 2017.

Primary and secondary outcome measures All participants completed a self-administered questionnaire that solicited information concerning demographics, smoking behaviour, self-rated suitability for being a counsellor, the knowledge and skills learnt from training courses and the TPB construct.

Results The factors of perceived behavioural control $(\beta=0.590, p<0.001)$, self-rated suitability for being a counsellor (acceptable vs not suitable, $\beta=0.436, p=0.001$; suitable vs not suitable, $\beta=0.510, p<0.001$ ), knowledge $(\beta=0.298, p=0.020)$ and professional specialty (military doctor vs non-military doctor, $\beta=0.198, p=0.034$ ) were found to be correlated with intention. However, attitude, subjective norms and descriptive norms were determined to be non-significant correlates. The model explained $59.7 \%$ of the variance for the intention to offer smoking cessation support ( $F[12,343]=44.864, p<0.001)$.

Conclusions To encourage smoking cessation counsellors to offer cessation support to smokers, policies should aim to increase their perceived behavioural control, knowledge and self-rated suitability for being a counsellor.

\section{INTRODUCTION}

Smoking prevalence has decreased annually since the implementation of tobacco control policies. From 2007 to 2015, smoking rates for men and women dropped from $39 \%$ to $35 \%$ and $8 \%$ to $6 \%$, respectively. ${ }^{12}$ However, the smoking rate among military members is higher than among the general population. ${ }^{3}$ In Taiwan, approximately $32 \%$ of military personnel reported being a current smoker
Strengths and limitations of this study

- The study sample was selected from the Taiwanese military.

- Analysis is based on the theory of planned behaviour (TPB), which accounts for subjective norms and descriptive norms.

- TPB constructs, knowledge, skills, professional confidence and smoking behaviour were included in the model.

- The model explained $59.7 \%$ of the variance for the intention to offer smoking cessation support among smoking cessation counsellors.

- This was a cross-sectional study, and the causal relationship between the factors and the intention to offer smoking cessation support must still be further explored.

in $2014,{ }^{4}$ exceeding the smoking rate of $16.4 \%$ in the adult population. ${ }^{5}$

Tobacco use negatively affects fitness and health. Some studies have indicated that military personnel who smoke tend to lack the fitness to serve and have high training costs. ${ }^{67}$ Furthermore, cigarette smoking was related to a higher risk of hospitalisation. ${ }^{8}$ As a result, more strategies to reduce smoking among military personnel are necessary.

Health professionals, such as doctors, dentists, pharmacists, nurses and midwives, are the first line of contact with the public, and thus are a valuable means of disseminating information and advice concerning smoking cessation. ${ }^{9}$ However, reports have indicated that these professionals have relatively low intentions of taking actions to help patients stop smoking. ${ }^{10-13}$ The major barriers to delivering smoking cessation advice were lack of training, knowledge and 
access to smoking cessation resources. ${ }^{12} 1415$ Some studies have indicated that healthcare professionals who received relevant training were more likely to assist patients with smoking cessation and had more success encouraging smoking abstinence among patients than untrained professionals. ${ }^{1516}$ Thus, training is an effective means of increasing health professionals' motivation and ability to provide patients with smoking cessation support.

In the Taiwanese military, the Ministry of National Defense-Medical Affairs Bureau established a team of smoking cessation counsellors in 2011. Smoking cessation counsellors undergo an 8-hour training course to acquire the knowledge and skills necessary to help smokers quit smoking. Each year, approximately 400 smoking cessation counsellors are trained. These smoking cessation counsellors are widely distributed in various units of the military to assist with the process of quitting smoking and to provide advice. However, smoking cessation counselling is secondary to the primary jobs of these counsellors; that is, their primary duty is not smoking cessation counselling. At the end of each year, the Ministry of National Defense-Medical Affairs Bureau publicly praises the outstanding smoking cessation counsellors; however, in 2015 , only $36.8 \%$ of smoking cessation counsellors actually provided advice to smokers because there were no additional rewards or positive feedback to encourage them to engage in smoking cessation tasks. ${ }^{17}$ Thus, it is crucial to understand the factors that motivate smoking cessation counsellors to actually offer smoking cessation tasks.

Ajzen and Fishbein ${ }^{18}$ proposed the theory of reasoned action (TRA) ${ }^{18}$ which postulates that people are rational individuals and their behaviour is intentional. Before taking an action, people consider the action and its outcomes and then decide whether to actually do it. The TRA considers two factors, attitude (ATT) and subjective norms $(\mathrm{SN})$. Subsequently, Ajzen ${ }^{19}$ proposed the theory of planned behaviour (TPB) to address perceived inadequacies of the TRA by adding perceived behaviour control (PBC). According to a review article, the TRA and its extension, the TPB, were most often used to predict health professionals' intentions, and had an overall frequency-weighted mean $\mathrm{R}^{2}$ of 0.59 . In addition, $\mathrm{PBC}$ was the major predictor associated with intentions to adopt clinical behaviours. ${ }^{20}$ One study indicated that all TPB variables were associated with intentions to provide tobacco treatment among dental hygienists. ${ }^{21}$ Another study found that ATT and PBC were correlated with mental health professionals' intentions to help patients stop smoking in the Netherlands. ${ }^{10}$ This demonstrated the efficacy of the TPB for explaining intentions among diverse types of professionals. ${ }^{20}$ According to Ajzen, the TPB could include additional predictors to increase its explanatory power concerning variance in behavioural intentions. ${ }^{19}$ Studies have reported that healthcare providers' knowledge, skills, professional confidence and their own smoking behaviour affected their likelihood of delivering tobacco cessation support. ${ }^{22-24}$ The $\mathrm{SN}$ in the TPB is an injunctive norm; however, a meta-analysis study discovered evidence that descriptive norms (DN) increased the variance explained in intention and had more influence than SN. ${ }^{25}$ Some studies that examined professionals' intentions to help patients stop smoking did not consider DN. We extended the TPB by including DN, knowledge, skills, professional confidence and the smoking behaviour of health professionals.

To date, there has been no research exploring the factors related to the intentions of smoking cessation counsellors in the military to offer smokers smoking cessation support. To address this knowledge gap, this study used the extended TPB to predict smoking cessation counsellors' intentions to offer smoking cessation support to military members.

\section{METHODS}

\section{Study design and participants}

This cross-sectional study selected trained smoking cessation counsellors in 2017. The participants were informed of the study purposes, and self-administered questionnaires were distributed after acquiring the participants' consent. They filled out the questionnaire and consented at the end of the training course.

\section{Patient and public involvement}

Participants were not involved in the design or conduct of this study.

\section{Measure}

This study used a self-administered questionnaire to collect data. The content validity of the questionnaire was assessed by experts, including healthcare scholars, educators and physicians. In addition, the face validity of the questionnaire was established through pilot testing with 30 smoking cessation counsellors, revising, and finalising. The questionnaire solicited information regarding demographics, smoking behaviour, self-rated suitability for being a counsellor, knowledge and skills learnt from training courses, the TPB variables and $\mathrm{DN}{ }^{22-26}$

Demographic variables included age, sex, educational attainment (senior high school or below, higher vocational school and college or above), military service branch (army, navy, air force and other), military rank (officer, non-commissioned officer and enlisted), professional specialty (military doctor or non-military doctor) and years of service.

The participants were asked about their smoking status (question: 'Do you currently smoke?' answer: 'Yes' or 'No'). Responses for self-rated suitability for being a counsellor were not suitable, acceptable or suitable.

The participants evaluated the level of perceived knowledge and skills that increased due to the training course. The evaluation items were designed according to the content and purpose of the training course. Knowledge was measured using five questions concerning professional knowledge, a counsellor's job responsibilities, a 
counsellor's work activities, the hazards of smoking and the national army tobacco prevention project; responses to each question were made using a five-point Likerttype scale with response choices ranging from 1 (strongly disagree) to 5 (strongly agree). A mean score was derived, and a higher score more strongly indicated that a participant had acquired knowledge from the training course. The scale exhibited adequate internal consistency $(\alpha=0.91)$. Skills were measured with six questions concerning consultation skills, the ability to communicate between units, the use of smoking cessation resources, the provision of education, the development of intervention methods and the assessment of the effectiveness of interventions. Responses ranged from strongly disagree (1) to strongly agree (5), again using a Likert-type scale. A mean score (range $=1-5)$ was derived, and the scale exhibited adequate internal consistency $(\alpha=0.95)$.

TPB variables included ATT, SN, PBC and intention. The questionnaire was designed according to guidelines in Ajzen ${ }^{27}$ and another study. ${ }^{26}{ }^{27}$ Each question was answered on a seven-point scale (ranging from strongly disagree to strongly agree). ATT was assessed by the question: 'The smoking cessation counsellors have an effective role in smoking cessation in the military'. The SN included two subscales (military smokers and superior officers) based on normative beliefs (NB) and motivations to comply (MC). NB included two statements: 'Most military smokers think that a smoking cessation counsellor should offer them smoking cessation support' and 'Most superior officers think that a smoking cessation counsellor should offer military smokers smoking cessation support'. Cronbach's alpha was 0.70. MC was evaluated by responses to the following statements: 'I am willing to comply with military smokers' wishes that I offer them smoking cessation support' and 'I am willing to comply with superior officers' wishes that I offer military smokers smoking cessation support'. Cronbach's alpha was 0.81 . Each NB was multiplied by the corresponding MC. The DN was measured by responses to the statement 'Most of my smoking cessation counsellor's colleagues offer military smokers smoking cessation support'. PBC was measured by responses to the statement 'I feel confident that I could offer military smokers smoking cessation support if I wanted to'. Intention was assessed by responses to one item: 'I want to offer smoking cessation support'.

\section{Data analysis}

Statistical analysis was conducted using the IBM SPSS Statistics V.22.0. Continuous variables (age, years of service, knowledge and skills) were represented as mean and SD. Categorical variables (sex, educational attainment, military service branch and military rank) were represented as frequencies and percentages. The TPB was scored by calculating the mean and SD. In addition, independent t-tests, one-way analysis of variance and Pearson correlation were performed to assess the differences between demographics and the main outcome variable. Furthermore, we predicted the intention to offer smoking cessation support using a linear regression model. Variation inflation factor (VIF) analysis was used to detect multicollinearity among the independent variables. When VIF was $\geq 10$, the variable was removed.

\section{RESULTS}

\section{Demographics}

The overall response rate was $100 \%$. The mean age of participants was 27.72 years $(\mathrm{SD}=5.57)$, and the majority were male $(n=300,70.6 \%)$. Most respondents had graduated from college or above $(\mathrm{n}=215,50.5 \%)$. Regarding military service branch, nearly half the participants served in the army $(n=220,51.6 \%), 18.5 \%(n=79)$ in the navy, $16.0 \%(\mathrm{n}=68)$ in the air force and $13.8 \%(\mathrm{n}=59)$ in other capacities. Most respondents were non-commissioned officer $(n=217,51.5 \%)$. Approximately half

Table 1 Demographic characteristics of the sample $(n=432)$

\begin{tabular}{ll}
\hline Variables & $\mathbf{n}(\%) /$ mean \pm SD \\
\hline Age & $27.72 \pm 5.57$ \\
Sex & $300(70.6)$ \\
\hline Male & $125(29.4)$ \\
\hline Female & \\
\hline Educational attainment & $132(31.0)$ \\
\hline Senior high school or below & $79(18.5)$ \\
\hline Higher vocational school & $215(50.5)$ \\
\hline College or above & \\
\hline Military service branch & $220(51.6)$ \\
\hline Army & $79(18.5)$ \\
\hline Navy & $68(16.0)$ \\
\hline Air force & $59(13.8)$ \\
\hline Other* & \\
\hline Military rank & $83(19.7)$ \\
\hline Officer & $217(51.5)$ \\
\hline Non-commissioned officer & $121(28.7)$ \\
\hline Enlisted & \\
\hline Professional specialty & $177(44.9)$ \\
\hline Non-military doctor & $217(55.1)$ \\
\hline Military doctor & $4.86 \pm 5.10$ \\
\hline Years of service & $76(17.6)$ \\
\hline Smoking & $63(15.1)$ \\
\hline Self-rated suitability for being a counsellor \\
\hline Not suitable & $207(49.8)$ \\
\hline Acceptable & $146(35.1)$ \\
\hline Suitable & $4.02 \pm 0.58$ \\
\hline Skills† & $3.86 \pm 0.68$ \\
\hline & \\
\hline Onowledge† & \\
\hline
\end{tabular}

*Others included military police force, reserve force and others. †Ranges from 1 to 5 . 


\begin{tabular}{|c|c|c|c|}
\hline \multirow[b]{2}{*}{ TPB variables } & \multirow[b]{2}{*}{ Mean \pm SD } & \multicolumn{2}{|c|}{ Intention } \\
\hline & & $\mathbf{R}$ & P value \\
\hline Intention* & $5.16 \pm 1.28$ & - & \\
\hline ATT* $^{*}$ & $4.44 \pm 1.37$ & 0.413 & $<0.001$ \\
\hline \multicolumn{4}{|l|}{ SN† } \\
\hline Military smokers & $20.78 \pm 10.34$ & 0.407 & $<0.001$ \\
\hline Superior officers & $21.42 \pm 10.64$ & 0.450 & $<0.001$ \\
\hline $\mathrm{DN}^{*}$ & $4.45 \pm 1.39$ & 0.353 & $<0.001$ \\
\hline $\mathrm{PBC}^{*}$ & $5.01 \pm 1.24$ & 0.730 & $<0.001$ \\
\hline
\end{tabular}

${ }^{\star}$ Ranges from 1 to 7 .

†Ranges from 1 to 49 .

ATT, attitude; DN, descriptive norms; PBC, perceived behaviour control; SN, subjective norms; TPB, theory of planned behaviour.

were military doctors $(\mathrm{n}=217,55.1 \%)$. The mean years of service was 4.86 years $(\mathrm{SD}=5.10)$. Approximately, $18 \%$ were smokers. Most participants self-rated their suitability for being a counsellor as acceptable $(n=207,49.8 \%)$. The mean knowledge and skills were $4.02(\mathrm{SD}=0.58)$ and 3.86 $(\mathrm{SD}=0.68)$, respectively (table 1$)$.

\section{TPB construct}

Mean scores for intention, ATT, DN and PBC were above the scale midpoint, but the SN was low (table 2). The mean score of the study participants for intention to provide smoking cessation support was 5.16 on a scale of $1-7$. The mean ATT was 4.44 on a scale of $1-7$. The SN included two subscales: military smokers had a mean score of 20.78 on a scale of 1-49 and superior officers had a mean score of 21.42 on a scale of $1-49$. The mean score for $\mathrm{DN}$ was 4.45 on a scale of $1-7$. The mean PBC score was 5.01 on a scale of $1-7$.

\section{Factors associated with the intention to provide smoking cessation support}

In the univariate analysis, military rank, professional specialty, self-rated suitability for being a counsellor, knowledge and skills were significantly related to the intention to offer smoking cessation support (table 3). The TPB variables of ATT, SN (military smokers), SN (superior officers), DN and PBC were positively correlated with the intention to provide smoking cessation support (table 2). Table 4 presents the results of the linear regression analysis of the intention to offer smoking cessation support. After adjusting for the significant demographics and TPB variables, professional specialty $(\beta=0.198, p=0.034)$, selfrated suitability for being a counsellor (acceptable vs not suitable, $\beta=0.510, p=0.001$; suitable vs not suitable, $\beta=0.510, p<0.001)$, knowledge $(\beta=0.298, p=0.020)$ and PBC $(\beta=0.590, p<0.001)$ were significantly associated with the intention to offer smoking cessation support. The model explained $59.7 \%$ of the variance for the intention to offer smoking cessation support $(\mathrm{F}=44.864, \mathrm{p}<0.001)$.
Table 3 Univariate analysis of demographics and intention to offer smoking cessation support of the sample ( $n=432)$

\begin{tabular}{|c|c|c|}
\hline \multirow[b]{2}{*}{ Variables } & \multicolumn{2}{|l|}{ Intention } \\
\hline & Mean \pm SD/R & $P$ value \\
\hline Age & 0.016 & 0.746 \\
\hline Sex & & 0.625 \\
\hline Male & $5.19 \pm 1.31$ & \\
\hline Female & $5.12 \pm 1.20$ & \\
\hline Educational attainment & & 0.911 \\
\hline Senior high school or below & $5.17 \pm 1.28$ & \\
\hline Higher vocational school & $5.10 \pm 1.39$ & \\
\hline College or above & $5.17 \pm 1.24$ & \\
\hline Military service branch & & 0.235 \\
\hline Army & $5.16 \pm 1.19$ & \\
\hline Navy & $5.15 \pm 1.51$ & \\
\hline Air force & $4.96 \pm 1.32$ & \\
\hline Other* & $5.42 \pm 1.18$ & \\
\hline Military rank & & 0.022 \\
\hline Officer & $5.46 \pm 1.19$ & \\
\hline Non-commissioned officer & $5.01 \pm 1.30$ & \\
\hline Enlisted & $5.21 \pm 1.26$ & \\
\hline Professional specialty & & 0.029 \\
\hline Non-military doctor & $5.03 \pm 1.31$ & \\
\hline Military doctor & $5.32 \pm 1.24$ & \\
\hline Years of service & -0.022 & 0.658 \\
\hline Smoking & & 0.255 \\
\hline No & $5.20 \pm 1.27$ & \\
\hline Yes & $5.04 \pm 1.33$ & \\
\hline \multicolumn{2}{|c|}{ Self-rated suitability for being a counsellor } & $<0.001$ \\
\hline Not suitable & $4.29 \pm 1.62$ & \\
\hline Acceptable & $5.11 \pm 1.12$ & \\
\hline Suitable & $5.63 \pm 1.11$ & \\
\hline Knowledge† & 0.465 & $<0.001$ \\
\hline Skills† & 0.467 & $<0.001$ \\
\hline
\end{tabular}

*Others included military police force, reserve force and others. †Ranges from 1 to 5 .

\section{DISCUSSION}

To the best of our knowledge, this is the first study to use the extended TPB to explain the intention to offer smoking cessation support among smoking cessation counsellors in the military. This study demonstrated that the level of a smoking cessation counsellor's intention to offer smoking cessation support in the Taiwanese military was above the scale midpoint (5.16 on a scale of $1-7)$. The model explained $59.7 \%$ of the variance for the intention to offer smoking cessation support, which was higher than in other research. ${ }^{28}$ Our study determined that PBC was the most critical factor influencing the intention to offer smoking cessation support among this sample of 
Table 4 Linear regression of intention to offer smoking cessation support of the sample $(n=432)$

\begin{tabular}{|c|c|c|}
\hline \multirow[b]{2}{*}{ Variables } & \multicolumn{2}{|l|}{ Intention } \\
\hline & $\beta(95 \% \mathrm{Cl})$ & $P$ value \\
\hline \multicolumn{3}{|l|}{ Military rank } \\
\hline Officers & Reference & \\
\hline $\begin{array}{l}\text { Non-commissioned } \\
\text { officers }\end{array}$ & $-0.133(-0.364$ to 0.098$)$ & 0.258 \\
\hline Private & $<0.001(-0.265$ to 0.264$)$ & 0.997 \\
\hline \multicolumn{3}{|l|}{ Professional specialty } \\
\hline Non-military doctor & Reference & \\
\hline Military doctor & 0.198 (0.015 to 0.380$)$ & 0.034 \\
\hline \multicolumn{3}{|c|}{ Self-rated suitability for being a counsellor } \\
\hline Not suitable & Reference & \\
\hline Acceptable & $0.436(0.180$ to 0.692$)$ & 0.001 \\
\hline Suitable & $0.510(0.226$ to 0.793$)$ & $<0.001$ \\
\hline Knowledge* $^{\star}$ & 0.298 (0.047 to 0.549$)$ & 0.020 \\
\hline Skill $^{*}$ & $0.031(-0.183$ to 0.245$)$ & 0.775 \\
\hline \multicolumn{3}{|l|}{ TPB variables } \\
\hline ATT† & $0.068(-0.006$ to 0.141$)$ & 0.072 \\
\hline \multicolumn{3}{|l|}{$\mathrm{SN} \ddagger$} \\
\hline Military smokers & $0.002(-0.010$ to 0.014$)$ & 0.711 \\
\hline Superior officers & $0.007(-0.005$ to 0.019$)$ & 0.237 \\
\hline $\mathrm{DN} \dagger$ & $-0.025(-0.101$ to 0.050$)$ & 0.509 \\
\hline $\mathrm{PBC} \dagger$ & 0.590 (0.496 to 0.685$)$ & $<0.001$ \\
\hline
\end{tabular}

$\mathrm{F}=44.864, \mathrm{p}<0.001, \mathrm{R}^{2}=61.1 \%$ and adjusted $\mathrm{R}^{2}=59.7 \%$.

*Ranges from 1 to 5 .

†Ranges from 1 to 7 .

‡Ranges from 1 to 49 .

ATT, attitude; DN, descriptive norms; PBC, perceived behaviour control; SN, subjective norms; TPB, theory of planned behaviour.

smoking cessation counsellors. In addition, knowledge, self-rated suitability for being a counsellor and professional specialty were also related to the intention to offer smoking cessation support. However, ATT, SN and DN were unrelated to the intention to offer smoking cessation support. The findings of this study may have implication for designing strategies to encourage healthcare professionals to provide smoking cessation services.

The mean score for the intention to offer smoking cessation support among smoking cessation counsellors was 5.16, which was higher than that of the staff at a state psychiatric hospital in the USA (4.3) ${ }^{28}$ This may be because patients with mental illnesses were less likely to receive advice to quit smoking than those without mental illnesses. ${ }^{29}$

A systematic review of the literature concerning the factors influencing health professionals' intentions related to clinical practice discovered that the TRA or its extension, the TPB, was most often used. Different studies using social cognitive theories to explain healthcare professionals' behavioural intention demonstrated different levels of efficacy with different types of professionals and behaviours. ${ }^{20}$ Many studies have used the TPB as a framework to examine the intention to provide smoking cessation support and the results were not consistent. For example, two studies indicated that all ТРB variables were associated with the intention to provide tobacco treatment among staff at a psychiatric facility and among dental hygienists. ${ }^{21} 28$ Another study, examined by Blankers $e t a l,{ }^{10}$ assessed mental health professionals' intentions for providing smoking cessation support to patients and discovered that ATT and PBC were the strongest identified correlates of intention. However, we determined that only $\mathrm{PBC}$ was a predictor of intention among smoking cessation counsellors in the military; ATT, SN and DN were not related to intention. The effect of ATT, $\mathrm{SN}$ and DN declined after controlling for TPB and other factors may due to the intercorrelation. Therefore, the predictors may be relevant and denoted that interventions aimed at increasing the intention to offer smoking cessation support should focus mainly on PBC and to a lesser extent ATT, SN and DN. In our study, approximately half of the smoking cessation counsellors were non-military doctors with insufficient professional knowledge regarding smoking cessation. Non-military doctors may have lower confidence in providing smokers smoking cessation support than military doctors, implying that training courses to improve PBC may be a key means of enhancing smoking cessation counsellors' intentions to offer smoking cessation support. In our study, ATT and intention were correlated in the univariate analysis but the relationship disappeared after controlling for the significant demographic and TPB variables, which was inconsistent with other studies. ${ }^{10} 2128$ The mean of ATT in the study was 4.44 (scores ranged from 1-7), which was lower than among staff at a psychiatric facility (4.69, scores ranged from 1-7) and among dental hygienists (4.0, scores ranged from 1-5).$^{21}{ }^{28}$ This may be the reason why ATT was not a major factor for intention. In our study, neither the SN of military smokers nor that of superior officers was below the midpoint, and no relationship was evident between $\mathrm{SN}$ and intention, which was consistent with other studies of mental health professionals. ${ }^{10}$ A possible explanation for this is that intention is an individual idea but SN emphasises the desires of others. Although we included DN as an additional predictor in the TPB, DN was not related to intention. This means that the influence of peers was low.

In our study, the correlation of knowledge and skills with intentions were similar in the univariate analysis. But after controlling for related factors, the association between skills and intentions was not significant. This finding was consistent with a systematic review that determined that the most commonly identified barrier to providing smoking cessation interventions in a hospital was a lack of knowledge ${ }^{30}$ However, a study indicated that knowledge and skill were related to physical therapists' intentions to counsel for smoking cessation. ${ }^{23}$ It could be due to inconsistencies in measuring knowledge and skill. 
In addition, skill was a more important factor of behaviour than knowledge as a prior systematic review study elaborated among health professionals. ${ }^{20}$ Furthermore, the participants in our study were newly trained and their actual behaviour of providing smoking cessation support was unknown. As a result, the potential influence of skill on behaviour was still paying attention to and further studied. Military doctors, in our study, had higher intentions to offer smoking cessation support than non-military doctors, perhaps because military doctors received relevant medical training in school and possessed more smoking-related knowledge than non-military doctors. This finding also underscored the importance of knowledge. Thus, a training programme is a key method to strengthen smoking cessation counsellors' knowledge.

Smoking cessation counsellors who self-rated their suitability for being a counsellor as 'not suitable' had less intention of offering smoking cessation support than those who self-rated as 'acceptable' or 'suitable'. This indicated that counsellors' beliefs about their own capacities were a factor that increased the intention to offer smoking cessation support. ${ }^{24}$

This study was the first study to use the extended TPB to explore intentions to offer smoking cessation support in the military. However, this study had several research limitations. The study was a cross-sectional study, and the relationship between factors and the intention to offer smoking cessation support was correlational. The causal relationship must still be further explored. In addition, because the participants in the study were a representative sample in 2017, the results cannot be generalised to the entire population of smoking cessation counsellors in the military. However, we used a census study method to collect data, and the response rate was $100 \%$; therefore, the bias of results was minimised.

\section{CONCLUSIONS}

This study demonstrated that PBC was the strongest correlate of the intention of offering smoking cessation support among smoking cessation counsellors in the military. In addition, self-rated suitability for being a counsellor, professional specialty and knowledge were also correlated with intention. According to our findings, designing interventions to strengthen PBC would be a feasible strategy for increasing smoking cessation counsellors' intentions to offer smoking cessation support. Although intention significantly predicted behaviour, ${ }^{26}$ future studies could evaluate the TPB construct on actual behaviour.

\section{Author affiliations}

${ }^{1}$ School of Public Health, National Defense Medical Center, Taipei, Taiwan

${ }^{2}$ Graduate Institute of Life Science, National Defense Medical Center, Taipei, Taiwan

${ }^{3}$ School of Medicine, National Defense Medical Center, Taipei, Taiwan

${ }^{4}$ Department of Family and Community Medicine, Tri-Service General Hospital,

Taipei, Taiwan

${ }^{5}$ Center for General Education, National Defense Medical Center, Taipei, Taiwan
Contributors SK, C-MC, F-GL and Y-LC designed the study and wrote the protocol. Y-LC, C-HL, S-LH, Y-WC and W-HF conducted literature searches and provided summaries of previous research studies. Y-LC and Y-CC conducted the statistical analysis. Y-LC wrote the first draft of the manuscript and all authors contributed to interpreting the results, and have approved the final manuscript.

Funding This research was supported by the Ministry of National DefenseMedical Affairs Bureau (MAB-106-088), Taiwan, ROC.

Competing interests None declared.

Patient consent for publication Obtained.

Ethics approval Ethical approval is provided by the Institutional Review Board of the Tri-Service General Hospital, National Defense Medical Center (1-106-05-029).

Provenance and peer review Not commissioned; externally peer reviewed.

Data sharing statement Data are available from the Dryad Digital Repository (https://doi.org/10.5061/dryad.798d8m6).

Open access This is an open access article distributed in accordance with the Creative Commons Attribution Non Commercial (CC BY-NC 4.0) license, which permits others to distribute, remix, adapt, build upon this work non-commercially, and license their derivative works on different terms, provided the original work is properly cited, appropriate credit is given, any changes made indicated, and the use is non-commercial. See: http://creativecommons.org/licenses/by-nc/4.0/.

\section{REFERENCES}

1. World Health Organization. WHO report on the global tobacco epidemic 2017-Monitoring tobacco use and prevention policies. 2017 http://apps.who.int/iris/bitstream/handle/10665/255874/ 97892415? sequence=1 (Accessed 15 Aug 2018).

2. $\mathrm{Ng} \mathrm{M}$, Freeman MK, Fleming TD, et al. Smoking prevalence and cigarette consumption in 187 countries, 1980-2012. JAMA 2014;311:183-92.

3. Nelson JP, Pederson LL. Military tobacco use: a synthesis of the literature on prevalence, factors related to use, and cessation interventions. Nicotine Tob Res 2008;10:775-90.

4. Chu NF, Lin FH, Wu YC, Yc W. Prevalence and Trends of Cigarette Smoking Among Military Personnel in Taiwan: Results of 10-Year Anti-Smoking Health Promotion Programs in Military. Mil Med 2017;182:e1933-7.

5. Administration HP; Ministry of Health and Welfare Executive. Taiwan tobacco control annual report. 2015 http://tobacco.hpa.gov.tw/Show. aspx?Menuld=416 (Accessed 15 Aug 2018).

6. Klesges RC, Haddock CK, Chang CF, et al. The association of smoking and the cost of military training. Tob Control 2001;10:43-7.

7. Bridger R, Munnoch K, Dew A, et al. Smoking, BMI and psychological strain and fitness in the Naval Service. Occup Med 2009;59:195-6.

8. Woodruff SI, Conway TL, Shillington AM, et al. Cigarette smoking and subsequent hospitalization in a cohort of young U.S. Navy female recruits. Nicotine Tob Res 2010;12:365-73.

9. World Health Organization (WHO). WHO urges health professionals to engage in tobacco control. http://www.who.int/mediacentre/news/ releases/2005/pr22/en/ (Accessed 15 Aug 2018).

10. Blankers $M$, Buisman $R$, Hopman $P$, et al. Modelling intentions to provide smoking cessation support among mental health professionals in the Netherlands. Tob Induc Dis 2016;14:32.

11. Girvalaki C, Papadakis S, Vardavas C, et al. Smoking cessation delivery by general practitioners in Crete, Greece. Eur J Public Health 2018;28:542-7.

12. Ford P, Tran P, Keen B, et al. Survey of Australian oral health practitioners and their smoking cessation practices. Aust Dent $J$ 2015;60:43-51

13. Abdullah AS, Qiming F, Pun V, et al. A review of tobacco smoking and smoking cessation practices among physicians in China: 1987-2010. Tob Control 2013;22:9-14.

14. Klink K, Lin S, Elkin Z, et al. Smoking cessation knowledge, attitudes, and practice among community health providers in China. Fam Med 2011;43:198-200.

15. Li KW, Chao DV. Current practices, attitudes, and perceived barriers for treating smokers by Hong Kong dentists. Hong Kong Med J 2014;20:94-101.

16. Carson KV, Verbiest ME, Crone MR, et al. Training health professionals in smoking cessation. Cochrane Database Syst Rev 2012:CD000214.

17. Medical Affairs Bureau, Ministry of National Defense, ROC (Taiwan). National Army Tobacco and Betel Nut Hazard Prevention Project, 2016. 
18. Ajzen I, Fishbein M. Understanding attitudes and predicting social behavior, 1980.

19. Ajzen I. The theory of planned behavior. Organ Behav Hum Decis Process 1991;50:179-211.

20. Godin G, Bélanger-Gravel A, Eccles M, et al. Healthcare professionals' intentions and behaviours: a systematic review of studies based on social cognitive theories. Implement Sci 2008;3:36.

21. Freeman T, Roche AM, Williamson P, et al. What factors need to be addressed to support dental hygienists to assist their patients to quit smoking? Nicotine Tob Res 2012;14:1040-7.

22. Sarna L, Bialous SA, Wells M, et al. Frequency of nurses' smoking cessation interventions: report from a national survey. J Clin Nurs 2009;18:2066-77.

23. Bodner ME, Rhodes RE, Miller WC, et al. Predictors of physical therapists' intentions to counsel for smoking cessation: Implications for practice and professional education. Physiother Theory Pract 2018:1-10.

24. Michie S, Johnston M, Abraham C, et al. Making psychological theory useful for implementing evidence based practice: a consensus approach. Qual Saf Health Care 2005;14:26-33.
25. Rivis A, Sheeran P. Descriptive norms as an additional predictor in the theory of planned behaviour: A meta-analysis. Curr Psychol 2003;22:218-33.

26. Yusuf H, Kolliakou A, Ntouva A, et al. Predictors of dentists' behaviours in delivering prevention in primary dental care in England: using the theory of planned behaviour. BMC Health Serv Res 2016;16:44.

27. Ajzen I. Constructing a TPB questionnaire: Conceptual and methodological considerations, 2002.

28. Okoli CTC, Otachi JK, Kaewbua S, et al. Factors Associated With Staff Engagement in Patients' Tobacco Treatment in a State Psychiatric Facility. J Am Psychiatr Nurses Assoc 2017;23:268-78.

29. Mitchell AJ, Vancampfort D, De Hert M, et al. Do people with mental illness receive adequate smoking cessation advice? A systematic review and meta-analysis. Gen Hosp Psychiatry 2015;37:14-23.

30. Sharpe T, Alsahlanee A, Ward KD, et al. Systematic Review of Clinician-Reported Barriers to Provision of Smoking Cessation Interventions in Hospital Inpatient Settings. J Smok Cessat 2018:1-11 